\title{
End-user innovation of urban infrastructure: key factors in the direction of development
}

Ian R. Bartle BSC, BA, MA, PhD, CEng, MIET

Honorary Research Fellow, School of Engineering, University of Birmingham, Birmingham, UK

Chris J. Bouch BSC, MSC, CEng, MICE, MINCOSE

Senior Research Fellow, School of Engineering, University of Birmingham, Birmingham, UK (corresponding author: c.bouch@bham.ac.uk)

Chris J. Baker CEng, FICE, FIHT, FHEA, FRMetS

Professor of Environmental Fluid Mechanics, Birmingham Centre for Railway Research and Education, School of Engineering, University of Birmingham, Birmingham, UK

\author{
Chris D. F. Rogers Eur Ing, BSC, PhD, CEng, MICE, MCIHT \\ Professor of Geotechnical Engineering and Director, UKCRIC National \\ Buried Infrastructure Facility, School of Engineering, University of \\ Birmingham, Birmingham, UK
}

Is there such a thing as an urban direction to infrastructure innovation in today's rapidly expanding cities? City growth has driven evolution of urban infrastructure through a combination of technological, political and commercial innovations to produce today's top-down, centralised models; however, these now stand in the way of the innovation necessary to accommodate the city growth anticipated in the future. The significant investment set out in the UK government's National Infrastructure Delivery Plan provides an opportunity to address this problem. This paper postulates that applying a decentralised (bottom-up/user-led) approach to the provision of infrastructure can create the space necessary for a new direction of urban innovation to emerge. It draws on case study examples from the literature, where there have been innovations along these lines, to develop a theoretically informed understanding of what needs to be in place for them to be successful. These findings, together with data from semistructured interviews with key stakeholders, are used to assess the likelihood of a successful, decentralised approach to a proposed, large infrastructure redevelopment at Digbeth in Birmingham.

\section{Introduction}

Human populations of the world's cities are growing rapidly. 2007 was the year in which, for the first time in human history, over $50 \%$ of the world's population lived in cities (UN, 2007). It is estimated that by 2050 , that figure will have increased to $70 \%$ (UN, 2012a). Growth is being driven by a range of economic and social factors: chiefly, the ability of cities to provide people with basic needs and essential public goods; and, to act as forums in which people can realise their ambitions and aspirations, achieving a measure of contentment and happiness in the process (UN, 2012b).

Historically, city growth has driven evolution of urban infrastructure through a combination of technological, political and commercial innovations, resulting in today's top-down, centralised models of infrastructure service provision. Most modern networked infrastructures, including telecommunications, water services, railways and electricity, emerged in the nineteenth and early twentieth centuries from small-scale local developments (Egyedi and Mehos, 2012: pp. 6-8). In the midtwentieth century these grew and merged into local networks, which gradually became regional and national. Consolidation and standardisation followed, and in a process of 'path dependence' early choices became locked-in and characterised system progress to maturity (Edwards et al., 2007: pp. i-ii).
During this period of growth, networked infrastructures also came to be seen as essential public services, and thus subject to increasing state regulation with some companies, particularly after 1945, taken over by the state. National and regional monopolies thus emerged in the main infrastructure sectors, further establishing the dominance of the large-scale, topdown, centralised model.

Ironically, bearing in mind this history of innovation, today's centralised infrastructure stands in the way of further urban infrastructure innovation. However, it is recognised that urban infrastructure systems will have to go through increasingly rapid cycles of innovation to support anticipated, continuing population growth (Bettencourt et al., 2007). Moreover, although the term 'growth' in relation to cities is widely accepted as inevitable, this is not so in a spatial sense, and thus there is the added dimension of urban densification to add to the other contextual changes that infrastructure provision must accommodate: a changing climate, persistent austerity, shifts in societal and cultural attitudes, and so on (see e.g. GOfS, 2018; Rogers et al., 2014).

Cities are already society's main engine of innovation as witnessed by the positive correlation between population size and the number of patents produced (Bettencourt et al., 2007) 


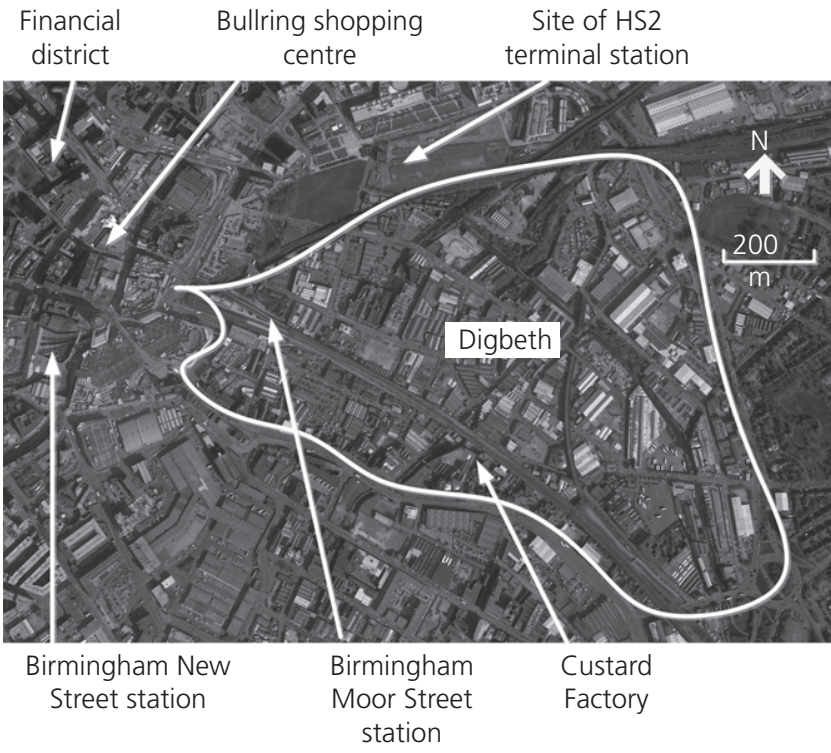

Figure 1. Aerial view showing Digbeth in relation to HS2 and Birmingham city centre (aerial image courtesy of Google Inc.)

and incremental infrastructure innovation continues to take place: for example, the telecommunications sector replacing copper wires with fibre optic cable. However, the long life cycle, capital intensive nature and 'top-down' organisational structure of much infrastructure are resistant to the emergence of new, disruptive, innovative ideas. The centralised approach can close off alternative ways of delivering value that might be particularly suitable for local and urban levels, while also being unresponsive to a range of technological, economic, organisational and social stimuli. Moreover, it can result in large-scale systems becoming too siloed within their respective sectors - that is cross-sectoral interdependencies, which have the potential to deliver benefits at lower levels, may not emerge in centralised systems.

With so much staked financially, commercially and socially on existing, centralised, urban infrastructure systems, and bearing in mind the pressing need for further cycles of infrastructure innovation, something significant is required to open things up to innovative ideas that are disruptive to the status quo. One possibility is the UK Government's National Infrastructure Delivery Plan, addressing perceived shortcomings in the country's infrastructure with a pipeline of infrastructure projects stretching out to 2021 , valued at $£ 483$ billion (IPA, 2016). Historically, the United Kingdom has invested heavily in world-class infrastructure that has helped underpin the country's economic growth; however, more recently, the UK's approach has been criticised as 'timid, uncoordinated, incremental, wasteful in its procurement, and insufficiently targeted', with the result that the infrastructure is ageing and no longer fit for purpose (HMT, 2010: p. 3). The situation provides an opportunity to explore a decentralised approach to infrastructure that can support a bottom-up, end-user approach to innovation.

The National Infrastructure Plan covers a wide range of infrastructure projects, including the London to Birmingham high-speed rail scheme (HS2). The Birmingham terminus at Curzon Street is seen as a driver for significant redevelopment of the adjoining Digbeth area, about $1 \mathrm{~km}$ east of Birmingham city centre (see Figure 1). As with the country generally, Digbeth redevelopment will require significant new infrastructure, particularly energy, transport, water and information and communications technology (ICT). Birmingham City Council's HS2 Curzon Street Masterplan has identified Digbeth as a 'creative zone', and as a 'place for growth' (BCC, 2014). Digbeth is portrayed in the Masterplan as an 'historic setting' (p. 20), and as having 'established itself as the home of a diverse and dynamic working community of digital and creative businesses' (media, arts, crafts, design, advertising, fashion, software) (p. 36). It is hoped that its historic character will be maintained, while at the same time being integrated into the new city space around the station.

In the context of the proposed Digbeth project, this paper postulates that a more decentralised (bottom-up/user-led) approach to infrastructure provision can create the space needed for a disruptive new approach to infrastructure innovation to emerge. Its aim is to explore the potential of this approach by drawing on case study examples from the literature, where there has been innovation along these lines, to develop a theoretically informed understanding of what needs to be in place for success; using semi-structured interviews with key stakeholders in Digbeth, to elicit their views on key factors in the bottom-up/user-led approach; and, using the findings to analyse and draw conclusions on the scope for a new direction in urban infrastructure innovation at Digbeth. The paper begins with some background on the Digbeth area before going on to review published literature on inverse infrastructures, user-led innovation, participatory design, and creative zones in cities. From this are elicited the factors that need to be in place for the decentralised approach to be successful. These factors are applied to the Digbeth area to assess its likelihood of success with decentralised infrastructure in place, and the findings are discussed in the context of their general application.

\section{Digbeth: then, now and in the future}

Digbeth can trace its history back to the twelfth century and the important trade route between Coventry and Birmingham. In the eighteenth and nineteenth centuries it was a major 
centre of industry with many workers living there, often in poor conditions. Today, all of the slum housing has been demolished and Digbeth is predominantly made up of lowrise, brick-built factories and warehouses, with a scattering of grander Victorian architecture and 'islands' of terraced housing (Dargue, 2016), as shown in Figure 2.

In the last 20 years, creative industries (media, design, digital, art galleries, TV production) have developed in and around, a development known as the Custard Factory (see Figure 1). The Custard Factory was established in 1837 by the firm of Alfred Bird to, as the name suggests, produce custard powder. It remained in production until 1964, after which it fell into disuse and became derelict. In 1993 redevelopment commenced and it became (in its own words) 'Birmingham's creative quarter' and 'the UK's leading destination for creative and digital businesses, independent shops and alternative culture outside London' (CF, 2018). Further space was provided in 2008 when Fazeley Studios were opened near the Custard Factory (about $200 \mathrm{~m}$ to the north east) (FS, 2018). Additionally, Digbeth is home to a wide range of small businesses working in sectors from social enterprise, through food distribution, to small-scale engineering. It has a small number of residential streets and an active community, there is a particularly vibrant night life (night clubs, music, arts and other cultural activities) and it has a strong Residents' Association.

Digbeth now stands on the threshold of a major new opportunity as a 'Creative Zone'. Birmingham City Council has recognised the potential that the nearby HS2 railway terminus (see Figure 1) has to help rejuvenate Digbeth, and has prepared a Masterplan (BCC, 2014) that envisages Digbeth building on the creative industries already there.

The Masterplan mentions some specific development ideas, but much of it is couched in terms of 'opportunities' for development. In this sense, the Masterplan is high level and rather general. Within the broad framework put forward, ideas are expected from investors, developers and others. On infrastructure it is similarly rather general. Other than proposals for the main transport routes, there is little on provision of other infrastructure and most of the detail is still to be decided on. The infrastructure ultimately provided will therefore depend very much on the opportunities that are taken up.

\section{The views of Digbeth stakeholders}

A small number of semi-structured interviews were held with senior members of important stakeholder groups in Digbeth to get an understanding of how they viewed decentralised provision of infrastructure. The groups covered were: architects, property developers, local authorities and innovation intermediaries. Broadly, they were supportive of the concept of a decentralised approach, although there was recognition that a hybrid approach (a mix of centralised and decentralised) would be likely to emerge. In particular, there was a desire among stakeholders to avoid a top-down redevelopment of the sort commonly, and perhaps unfairly, associated with major redevelopment opportunities. This can lead to an increase in rents, the flight of small businesses and a loss of the distinct character and vibrancy of an area.

Some stakeholders were concerned about whether Digbeth was big enough to support a decentralised approach to infrastructure. They pointed out that successful innovation in business results from a conjunction of numerous factors including: ideas, drive, spark, money, technology, knowledge, business support, networking and space. Without most, if not all, of these, innovation and business development is less likely. In its existing form, Digbeth has shown that it can provide the space, drive and spark (e.g. the Custard Factory), but there is the risk that it is rather separate and cut off from the main city centre 'business' area, where technology, knowledge, business support and networking is seen to be more abundant. A kind of 'horizontal connectivity' is required between different areas to make something substantial and innovative happen, but as yet this is missing in Digbeth.

Another limitation was that stakeholders were unable to give examples in Digbeth of bottom-up, user-driven infrastructure provision, with the exception of social infrastructure. Notwithstanding their broad support for the concept of decentralised infrastructure, there was some scepticism that infrastructure could be provided in a bottom-up way; the general view was that infrastructure is something provided by others. As will be seen later on, this reflects the study's findings in other creative areas, where the focus of stakeholders appears to be on expressing disappointment about the quality of existing infrastructure, notably broadband, rather than taking action to do something about it.

\section{Decentralised infrastructure innovation}

\subsection{Inverse infrastructures}

One of the most developed frameworks for decentralised provision of infrastructure comes from the Next Generation Infrastructures (NGinfra) knowledge institute based at Delft University in the Netherlands. Its findings are summarised in the book 'Inverse Infrastructures: Disrupting Networks from Below' (Egyedi and Mehos, 2012). Particular kinds of infrastructures are referred to as 'inverse' if they display features that are the opposite of the top-down, large-scale, technical system model that is dominant at the moment in infrastructure networks. Egyedi and Mehos describe the 'prominent and prototypical characteristics' of inverse infrastructures as: 'user-driven', 

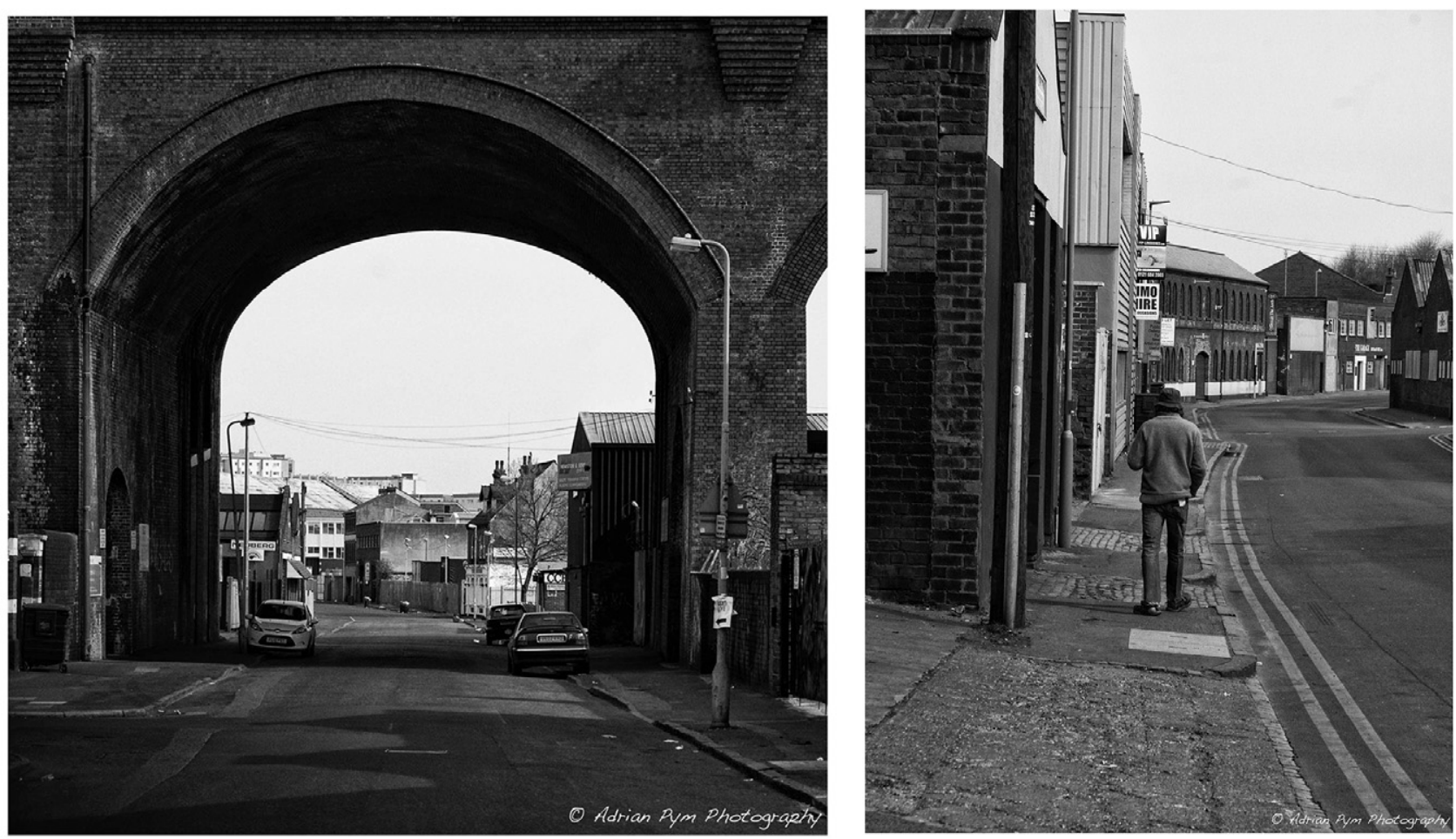

(1) Adrian Pym Photography

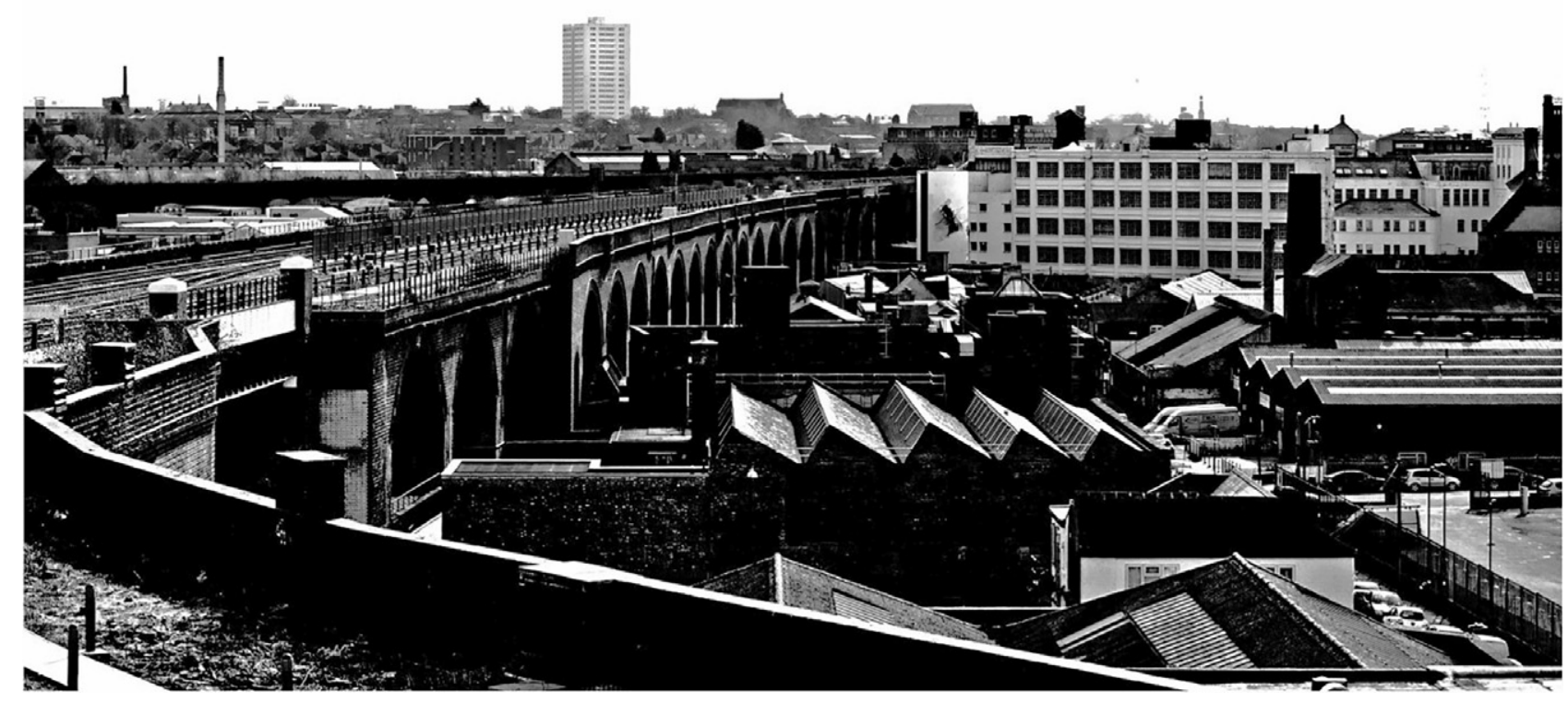

Figure 2. Views of Digbeth c.2000 (courtesy of Adrian Pym photography) 
'self-organisation', 'decentralisation', and 'bottom-up' (p. 4). Their research has found the following points.

- Users can have a more influential role in technological development than conventionally thought.

- Users can self-organise at a small-scale level to optimise a local situation, which can lead to further activity and interaction among users, triggering further development.

- In decentralised systems, all the major aspects of decision making, control, system development, business and investment are distributed among numerous different agents away from a central point, with institutional arrangements emerging through the interaction of multiple agents.

- Bottom-up influences come from the interests and actions of users of technology, citizens, communities and small businesses, rather than from network operators as is prevalent under current top-down arrangements.

The research covered a diverse range of case studies from different sectors, although the energy and ICT sectors tended to dominate. It found that an important condition required for the formation of inverse infrastructures is a high level of communication and trust. The availability of easy-to-use and powerful communications, afforded by the Internet and new ICT, is also seen as highly significant and helps to explain, perhaps, why many inverse infrastructures are in these technical fields.

Egyedi and Mehos found that common technical standards can enable the development of inverse infrastructures (p. 248). Standards can promote interoperability and interconnection between different systems, enabling small-scale new developments to be connected to, and operate within, existing centralised infrastructures. Standards also provide a degree of certainty about the infrastructure and market for new investors. In the case of inverse infrastructures, therefore, standards prove to be an enabler of innovation whereas they are often considered to be inhibitors of innovation in the established, top-down infrastructure sectors (e.g. Leach et al., 2015). This reflects the need for all of the systems of governance to be engineered appropriately to the urban intervention being proposed (Rogers, 2018).

The incentives for participation in inverse infrastructures are wide ranging and instructive about the circumstances under which they can emerge. The main incentives highlighted by the research (pp. 247-248) are as mentioned below.

- Better functionality of infrastructure.

- Financial benefits to consumers, notably through drawing on local advantages not easily gained by a one-size-fits-all centralised supplier.

- Independence from central suppliers and control over service.
Interest and curiosity - the satisfaction individuals can get from realising and developing their expertise in areas such as local Wi-Fi.

- Sharing, mutual support and the sense of belonging that can come from being active within a local community initiative.

The inverse infrastructures work recognises that some central and local government policies are required to encourage and support inverse infrastructures, and yet this will always be in tension with the core idea of inverse infrastructures. Therefore, a delicate balancing act will be required. The suggested policies (pp. 251-252) include the below listed points.

- Incentives to enable the formation of networks.

- Interactive learning and community engagement.

- Research and development subsidies.

- Subsidies to support upscaling.

- Pricing regimes to allow, for example, minimum prices for services.

- Standards on interoperability and inter-connection (to enable inverse infrastructures to connect and operate within centralised, large-scale systems).

\subsection{User-led innovation}

The idea of the user taking a prominent role in innovation is established in the wider literature, notably Eric von Hippel (2005) 'Democratizing Innovation', which focuses on innovation in relation to manufactured products and software. Von Hippel describes a world in which 'users of products and services - both firms and individual consumers - are increasingly able to innovate for themselves' (von Hippel, 2005: p. 1). This 'user-centred' innovation process is in contrast to the traditional model in which manufacturers undertake innovation in a closed way, and retain the knowledge gained, while users act primarily as a source of demand and revenue. Von Hippel argues that 'a growing body of empirical work shows that users are the first to develop many, and perhaps most, new industrial and consumer products. Further, the contribution of users is growing steadily as a result of continuing advances in computer and communications capabilities' (von Hippel, 2005: p. 2).

Von Hippel depicts a set of decentralised processes for technical innovation and introduces the role of specialist users (described as 'lead users'). Their importance comes from the specialist knowledge they have gained using the product and their desire to overcome problems encountered. Although innovative products are normally further developed and commercialised by established manufacturers, the importance of the knowledge of specialist users means they can continue to play a role with the manufacturer in product development.

Unfortunately, von Hippel's book does not discuss the role of the user in infrastructure innovation. However, there are some 
interesting discussions of user-led processes in the literature on infrastructure, particularly that relating to energy. Studies of sustainable, small-scale energy technologies (energy efficiency and renewable energy technologies) have shown the important role of the citizen-user, and have drawn on the work of von Hippel (Hyysalo et al., 2013; Ornetzeder and Rohracher, 2006).

\subsection{Participatory design}

An area of enquiry related to user-led innovation is that of 'participatory design'. As the name implies, the focus is on design rather than innovation, but it continues to move away from traditional, top-down processes, towards 'co-design' processes involving a wide range of actors, particularly users. When considering design in connection with users, distinctions can be drawn between

- design for users (users are the central focus in design, but their involvement is peripheral)

- design with users (users participate in the design process, although do not lead it)

- design by users (users lead in the design process).

Participatory design involves a clear shift from design for users, towards design with users and, to an extent, design by users.

The design of technological systems is a central feature of participatory design. The idea enables people affected by the technology they use to participate in a collaborative design process. While technological systems are the focus, there is an explicit social and political angle to it that goes well beyond 'merely the insertion of public dialogue within technological development practices' (Asaro, 2000: p. 1). It is about understanding how user-centred design and development fit into wider social and political frameworks.

Techniques and tools of participatory design include the use of 'co-design spaces' - which are not just physical spaces, but environments that encourage and are supportive of nonexperts - and design workshops, which can include the use of scenario techniques drawing on drama, theatre and design games (Liem and Sanders, 2011; Sanders and Westerlund, 2011). It is important that the processes are on-going, not oneoff. The literature on participatory design describes a range of applications in areas such as health and education, but there is no discussion on networked infrastructures (Frauenberger et al., 2015; Simonsen and Robertson, 2013).

\section{Creative zones in cities}

Innovation is seen to be an inherent feature of creative areas and industries - they are often entrepreneurial, early adopters of new ideas and technologies and they can stimulate further innovation and act as catalysts for economic regeneration (Evans, 2009; WF, 2009). In reports on innovation in creative industries, one of the most significant factors is the importance of networks: creative industries with strong networks tend to be more innovative (Evans, 2009; Nathan et al., 2012; WF, 2009). Thus, the close working of creative people, sometimes in the same building, 'may generate vital spark' (Nathan et al., 2012: p. 42). Similarly, an 'ecosystem of interconnected individuals' (physical and virtual proximity) is seen as vital for innovation (Foord, 2013: p. 55). At the local level, there are numerous interventions possible by local authorities to help generate networks and encourage development of creative industries (WF, 2009: p. 56). Local context, which defines features such as size, existing strengths, culture and history, is particularly important when considering interventions (WF, 2009) and all important when attempting to implement change in cities (Rogers, 2018).

Infrastructure is not totally absent from the literature. Numerous concerns are expressed about the need for the provision of good-quality infrastructure, notably broadband, for creative industries. However, as mentioned above, the general assumption is that this is provided externally. In a recent report on the development of digital 'Tech Cities' across the United Kingdom, concerns were aired by many of the companies surveyed about poor broadband infrastructure, but this did not translate through into bottom-up initiatives to improve matters (Tech City UK, 2016: p. 25). A small shift away from this mind set is evident in a report on creative industries by the Work Foundation (WF, 2009). Some users expressed frustration with having to accept the infrastructure they are given and there is a note of the need to consult business users first before making decisions about infrastructure provision (WF, 2009: p. 48).

Extending the notion of creative areas beyond industries normally associated with the creative sector reveals some examples of innovative infrastructure provision. One is King's Cross Central in London, the redevelopment of the area surrounding King's Cross Station, which, although not based primarily on creative industry, has parallels with Digbeth in that it is urban regeneration close to a major railway station. There, a company called Metropolitan Infrastructure Limited has been set up to manage the supply of a range of infrastructure services in the area. It is able to exploit opportunities from interdependencies between different infrastructure services and, being more proximate to the user than conventional infrastructure companies, take more of an enterprise/usercentred perspective on infrastructure provision.

\section{Key factors for decentralised infrastructure innovation}

The research has shown a wide range of factors to be important for a decentralised, end-user approach to infrastructure 
innovation. One is 'opportunity'; without an opportunity for innovation, it is impossible to make any progress. This is particularly important with regard to infrastructure, where the long life cycles and high sunk costs of existing infrastructure militate against anything other than incremental change. Situations where an existing infrastructure is life expired, such as that in Digbeth, are one source of opportunity for innovation.

If opportunity is there, then 'leadership' and 'lead users', may be the next priority, closely followed by issues of 'communication' and 'trust'. The top-down approach to infrastructure provision is well established, and multi-million pound infrastructure companies have a vested interest in maintaining the status quo. Therefore, change is unlikely to come about unless an individual, or small group of people, are willing to inject substantial amounts of energy into promoting a new idea. Technical skills are required as well as those of leadership, hence the importance of identifying lead users, and trust and communication within that team, and between the team and the wider world, will be critical to success. Physical 'connectivity' has also been found to be important. This can take the form of people being co-located in the same office, but can also be on a larger scale: the ability to move about in the city with ease, experience what is going on elsewhere and draw inspiration from that.

Leaders, lead users, trust and communications play a necessary part in providing the 'ideas', 'spark', 'knowledge' and 'networking' necessary to develop an innovative idea in the first place. However, they are not sufficient - 'incentives', 'money', 'technology', 'business support' and 'space' must be in the mix as well. Technological innovation often provides the springboard for wider innovation, but without money to support development new ideas are unlikely to get to market. Business support is important in situations where those leading do not have the full range of skills to tackle all the issues that will face a new business, and there needs to be sufficient incentive, whether commercial, reputational or intellectual, to make it worth persevering with the project.

Finally, there is a variety of what might seem to be dull, but no less important for that, factors, such as the 'policy environment', 'common technical standards' and 'business and social cultures'. A lack of supporting technical standards and regulations can be a major blockage to infrastructure innovation: for example, development of an electricity micro-generation idea could be killed off if the standards to support its connection to the national network are not in place. Similarly, government policy can be a boon or a deterrent: policies like a feed-in tariff for green energy could be very important to the micro-generation example above. And culture will have a big part to play in determining just how receptive banks and markets are to new ideas.

\section{Is Digbeth ready for the decentralised infrastructure approach?}

It is clear that the arrival of HS2 in Birmingham does provide an opportunity that could be addressed by the decentralised approach to infrastructure innovation. The existing infrastructure is old and is likely to prove unable to serve the planned development, while, other than some high-level ideas about transport provision, the HS2 Curzon Masterplan does not specify much in the way of infrastructure. Additionally, there is a desire among stakeholders to avoid a top-down redevelopment of the sort commonly, and perhaps unfairly, associated with major redevelopment opportunities. The door is potentially open, therefore, to an entirely new approach.

However, this research found no examples in Digbeth, other than for social infrastructure, of bottom-up infrastructure provision. Although the stakeholders appeared broadly supportive of the decentralised infrastructure concept, there was no real sense of newly emerging ideas on infrastructure. This is in line with study's findings in other creative areas, where stakeholder focus appears to be on expressing disappointment about the quality of infrastructure, notably broadband, and, occasionally, the wish for more say in what is provided. The general view is that infrastructure is something provided by others.

That said, Digbeth does have its leaders, lead users and examples of trust and communication. One of its distinctive features is its vibrant community and identity. Stakeholders pointed out that there is a wide range of small-scale, bottomup initiatives taking place in Digbeth: from art events and night life, to the development of sustainable urban landscapes and city food production. The Digbeth Residents' Association is a particularly important organisation at the heart of all this activity.

Despite examples of trust and communication being present, stakeholders felt that connectivity needed to be improved to help with the generation and development of new ideas perhaps what is lacking is a broker of conversations, or convenor of the necessary people and organisations, since it is far from clear with whom to converse or how to make the conversation happen. This role is now sometimes referred to as an intermediator, and if this role were to adopt a mechanism of consultation such as that proposed by Hunt and Rogers (2015), in which the views of all relevant stakeholders are amalgamated to create alternative future scenarios in which 'what if?' questions sit alongside 'why not?' revelations, then the path to radical change becomes far more comfortable. Linked to this was a concern about scale. There was a feeling that Digbeth is too cutoff from the city centre and as such the vital ingredients of innovation (drive, spark, money, technology, knowledge, business support, networking and space) are not there in sufficient quantity. 
In terms of government policy and regulation, there are several interventions that could encourage decentralised infrastructure provision. There are, for example, national schemes for energy saving, and favourable regulatory regimes (such as feed-in tariffs) for small-scale, renewable energy schemes. At the local level, there are also enterprise zones to encourage the development of small businesses and start-ups. Although all this could help small, innovative enterprises in infrastructure, none of them are distinctive in Digbeth.

Culturally, the picture is confused. There appears to be no outright rejection of the decentralised approach, but there does not seem to be any great belief in it either. What comes through strongly is maintenance of the status quo with regard to infrastructure provision: infrastructure services are provided by large corporations involving national networks, and it is for them to do the work necessary to improve infrastructure in Digbeth. At the same time, however, Digbeth has a number of examples of community-driven initiatives, so the drive and commitment are there. It may be that cultural aspects are linked very strongly to the issue of leaders and lead users mentioned earlier, and that change needs those individuals to step forward.

\section{Conclusions}

Historically, urban infrastructure innovation has had a clearly discernible direction: the invention and commercialisation of new technology on a small scale has developed over many years to achieve today's large-scale networked infrastructure systems. There seems to be, however, some justification in saying that this trajectory has run its course: within those systems it is possible to see continuing, incremental innovation, but infrastructure's large sunk costs and long life cycles are militating against more radical and disruptive innovation.

Further innovation of urban infrastructure is required to meet the challenges posed by urban population growth and the associated contextual changes in which this growth is projected to occur. It is suggested that a decentralised, end-user-driven method of urban infrastructure provision offers the chance to break away from the current paradigm and develop a new approach to infrastructure to address the challenges and opportunities emerging in the world's cities. The research has found eight key factors that need to be in place to support the decentralised approach and a new direction for urban infrastructure innovation

opportunity

- leadership and lead users

- communication and trust

- physical connectivity

- ideas, drive, spark, money, technology, knowledge, business support, networking and space

\begin{abstract}
technical standards
government policy

culture.
\end{abstract}

The Digbeth area of Birmingham, where there are plans for significant infrastructure redevelopment, was analysed using the eight key factors to see whether it would be suitable for application of the decentralised approach. The research found that while there was a distinct opportunity, and examples of community-initiated schemes were evident, there was little interest in applying the decentralised approach to infrastructure, largely because infrastructure is seen as something that is provided by others and, therefore, perhaps outside the scope of community action. The research did not, however, find any fundamental barriers to prevent application of the decentralised approach in the future, should the necessary leadership be found.

\section{Acknowledgements}

The authors gratefully acknowledge Engineering and Physical Sciences Research Council (EPSRC) and the Economic and Social Research Council (ESRC) for its funding under grants EP/P002021 (Urban Living Birmingham) and EP/K012398 (iBUILD) and Adrian Pym of Adrian Pym Photography (https://adrianpymphotography.co.uk/) for permission to reproduce his images of Digbeth.

\section{REFERENCES}

Asaro PM (2000) Transforming society by transforming technology: the science and politics of participatory design. Accounting, Management and Information Technologies 10: 257-290.

BCC (Birmingham City Council) (2014) Birmingham Curzon HS2: Masterplan for Growth. Birmingham City Council, Birmingham, UK.

Bettencourt LMA, Lobo J, Helbing D, Kuehnert C and West GB (2007) Growth, Innovation, Scaling, and the Pace of Life in Cities. The National Academy of Sciences of the USA, Washington, DC, USA.

CF (Custard Factory) (2018) http://www.custardfactory.co.uk/ (accessed 06/02/2018).

Dargue W (2016) William Dargue - A History of Birmingham Places and Place Names ... From A to Y: Digbeth. William Dargue, Birmingham, UK. See http://billdargue.jimdo.com/placenamesgazetteer-a-to-y/places-d/digbeth/ (accessed 06/02/2018).

Edwards PN, Jackson SJ, Bowker GC and Knobel C (2007) Understanding Infrastructure: Dynamics, Tensions, and Design. Report of a Workshop on 'History \& Theory of Infrastructure: Lessons for New Scientific Cyberinfrastructures'. University of Michigan, Ann Arbor, MI, USA. See http://htl.handle.net/2027.42/49353 (accessed 06/02/2018).

Egyedi T and Mehos D (eds) (2012) Inverse Infrastructures: Disrupting Networks from Below. Edward Elgar, Cheltenham, UK and Northampton, MA, USA.

Evans G (2009) Creative cities, creative spaces and urban policy. Urban Studies 46(5-6): 1003-1040. 
Foord J (2013) The new boomtown? Creative city to tech city in East London. Cities 33: 51-60.

Frauenberger C, Good J, Fitzpatrick G and Iversen OS (2015) In pursuit of rigour and accountability in participatory design. International Journal of Human-Computer Studies 74: 93-106.

FS (Fazeley Studios) (2018) http://www.fazeleystudios.com/ (accessed 06/02/2018).

GOfS (Government Office for Science) (2018) Future of Cities: An Overview of the Evidence. Government Office for Science, London, UK. See http://www.gov.uk/government/publications/future-ofcities-overview-of-evidence (accessed 06/02/2018).

HMT (Her Majesty's Treasury) (2010) National Infrastructure Plan 2010. Her Majesty's Treasury, London, UK.

Hunt DVL and Rogers CDF (2015) Aspirational City Futures: 3 Models for City Living - Workshops (Bristol and Birmingham). Foresight, Government Office for Science, London, UK.

Hyysalo S, Juntunen JK and Freeman S (2013) User innovation in sustainable home energy technologies. Energy Policy 55: 490-500.

IPA (Infrastructure and Projects Authority) (2016) National Infrastructure Delivery Plan 2016-2021. Infrastructure and Projects Authority, London, UK.

Leach JM, Boyko CT, Cooper RFD et al. (2015) Do sustainability measures constrain urban design creativity? Proceedings of the Institution of Civil Engineers - Urban Design and Planning 168(1): 30-41, https://doi.org/10.1680/udap.13.00034.

Liem A and Sanders EBN (2011) The impact of human-centred design workshops in strategic design projects. In Human Centered Design, HCII 2011, LNCS 6776 (Kurosu M (ed.)). Springer, Berlin and Heidelberg, Germany, pp. 110-119.

Nathan M, Vandore E and Whitehead R (2012) The Tale of Tech City: The Future of Inner East London's Digital Economy. Centre for London, London, UK.
Ornetzeder M and Rohracher H (2006) User-led innovations and participation processes: lessons from sustainable energy policies. Energy Policy 34: 138-150.

Rogers C (2018) Engineering future liveable, resilient, sustainable cities using foresight. Proceedings of the Institution of Civil Engineers - Civil Engineering 171(2): 1-7, https://doi.org/ 10.1680/jcien.17.00031.

Rogers CDF, Shipley J, Blythe P et al. (2014) Future Urban Living - A

Policy Commission Investigating the Most Appropriate Means for Accommodating Changing Populations and Their Needs in the Cities of the Future. University of Birmingham, UK. Sanders EBN and Westerlund B (2011) Experiencing, exploring, experimenting in and with co-design spaces. Nordic Design Research Conference 2011. NORDES, Helsinki, Finland, pp. $298-302$.

Simonsen J and Robertson T (eds) (2013) Routledge International Handbook of Participatory Design. Routledge, Abingdon, Oxon, UK.

Tech City UK (2016) https://www.swipe.to/5870dz (accessed 06/02/2018). UN (United Nations) (2007) Liveable Cities: The Benefits of Urban Environmental Planning. The United Nations Environment Programme, The Cities Alliance and Local Governments for Sustainability, Washington, DC, USA.

UN (2012a) Join the World Urban Campaign: Better City, Better Life. The United Nations - Habitat, Nairobi, Kenya.

UN (2012b) The State of the World's Cities 2012/2013: Prosperity of Cities. United Nations Human Settlements Programme, Nairobi, Kenya.

Von Hippel E (2005) Democratizing Innovation. The MIT Press, Cambridge, MA, USA.

WF (Work Foundation) (2009) Investing in Creative Industries. A Guide for Local Authorities. Work Foundation, London, UK.

\section{How can you contribute?}

To discuss this paper, please email up to 500 words to the editor at journals@ice.org.uk. Your contribution will be forwarded to the author(s) for a reply and, if considered appropriate by the editorial board, it will be published as discussion in a future issue of the journal.

Proceedings journals rely entirely on contributions from the civil engineering profession (and allied disciplines).

Information about how to submit your paper online is available at www.icevirtuallibrary.com/page/authors, where you will also find detailed author guidelines. 